\title{
Developmental Changes in Water Permeability Across the Alveolar Barrier in Perinatal Rabbit Lung
}

\author{
Ethan P. Carter, Fuminori Umenishi, Michael A. Matthay, and A.S. Verkman \\ Department of Medicine and Department of Physiology, Cardiovascular Research Institute, University of California, San Francisco, \\ San Francisco, California 94143
}

\begin{abstract}
Lung fluid is reabsorbed rapidly at birth to permit alveolar respiration. We reported previously that expression of aquaporins (AQP) 1, 4, and 5 in rat lung increased just after birth. The hypothesis was tested that the increased AQP expression is associated with increased osmotic water permeability $\left(P_{f}\right)$ between the airspace and capillary compartments. $P_{f}$ was measured in isolated perfused fetal and newborn rabbit lungs using a pleural surface fluorescence method (Carter, E.P., M.A. Matthay, J. Farinas, and A.S. Verkman. 1996. J. Gen. Physiol. 108:133-142). In response to perfusate osmolality increase from 300 to $600 \mathrm{mosM}$, initial rates of osmotic equilibration were $1.13 \pm 0.13 \mathrm{mosM} / \mathrm{s}$ at 0-12 $\mathrm{h}$ after birth, increasing to $1.52 \pm 0.19 \mathrm{mosM} / \mathrm{s}$ at $12-24 \mathrm{~h}$, and $1.83 \pm 0.10 \mathrm{mosM} / \mathrm{s}$ at $24-84 \mathrm{~h}$. Corresponding $P_{f}$ values (in $\mathrm{cm} / \mathrm{s} \times 10^{-2}$ ), computed from $\mathrm{d}[\operatorname{mos} M] / \mathrm{dt}$ and alveolar surface-to-volume ratios, were $1.03 \pm 0.11(0-12 \mathrm{~h})$, $1.51 \pm 0.16(12-24 \mathrm{~h})$, and $1.88 \pm 0.09(24-84 \mathrm{~h}) . \mathrm{P}_{\mathrm{f}}$ was relatively low in prenatal (1.22-1.27, fetal days 29 and 31) and adolescent $(1.25 \pm 0.08,21-\mathrm{d})$ rabbit lungs. To test for involvement of molecular water channels, measurements were made of Arrhenius activation energy $\left(E_{a}\right)$, mercurial inhibition, diffusional water permeability $\left(P_{d}\right)$, and AQP expression. Temperature-dependence measurements showed a $25 \%$ decrease in $\mathrm{E}_{\mathrm{a}}$ for $\mathrm{P}_{\mathrm{f}}$ in lungs $<1 \mathrm{~d}$ vs. $4 \mathrm{~d}$. $\mathrm{P}_{\mathrm{f}}$ was decreased $30 \%$ by $0.5 \mathrm{mM} \mathrm{HgCl}_{2}$ in $<1$-d lungs and $44 \%$ in 4 -d lungs. $P_{d}$ was $1.0 \times 10^{-5} \mathrm{~cm} / \mathrm{s}$ and did not change when $P_{f}$ was increased by $75 \%$. RNase protection assay showed increased transcript expression in the first $24 \mathrm{~h}$ after birth for rabbit isoforms of AQP1 and AQP4. These results provide the first functional data on water permeability in perinatal lung. The increased water permeability after birth may facilitate the maintenance of dry alveoli. (J. Clin. Invest. 1997. 100:10711078.) Key words: aquaporins • water transport • fluorescence $\cdot$ development $\bullet$ lung
\end{abstract}

Address correspondence to Alan S. Verkman, M.D., Ph.D., Cardiovascular Research Institute, 1246 Health Sciences East Tower, Box 0521, University of California, San Francisco, San Francisco, CA $94143-$ 0521. Phone: 415-476-8530; FAX: 415-665-3847; E-mail: verkman@ itsa.ucsf.edu

Received for publication 5 February 1997 and accepted in revised form 20 June 1997.

J. Clin. Invest.

(c) The American Society for Clinical Investigation, Inc. 0021-9738/97/09/1071/08 \$2.00

Volume 100, Number 5, September 1997, 1071-1078

http://www.jci.org

\section{Introduction}

The movement of water between the airspace and blood compartments of the lung is a developmentally and hormonally regulated process. During prenatal intrauterine life, the lungs remain filled by the continuous secretion of fluid whose composition is distinctly different from plasma and amniotic fluid (1). Fluid secretion is driven by chloride transport, resulting in osmotic water movement into the fluid-filled airspaces. At the onset of labor, fluid secretion falls by $\sim 50 \%$ (2), and reabsorption, driven by active sodium transport, begins (3). Reabsorption occurs largely by epithelial sodium channels $(\mathrm{ENaC})^{1}$ (4), with a primary stimulus for the onset of liquid absorption being a surge in fetal epinephrine levels associated with labor and delivery (5). A further stimulus for postnatal lung liquid clearance may be the increase in the partial pressure of oxygen immediately after birth $(6,7)$. By $12 \mathrm{~h}$ after birth, $80 \%$ of perinatal lung liquid is cleared (8-10). The ability to osmotically reabsorb fluid from the airspaces is retained throughout adult life (11-13).

In the adult lung, osmotic water movement is mediated by aquaporins (AQP), which are small hydrophobic membrane proteins $\left(\sim 30,000 \mathrm{M}_{\mathrm{r}}\right)$ with homology to the major intrinsic protein of lens $(14,15)$. Three AQPs are expressed in the adult lung in distinct locations: AQP1 (CHIP28) in the capillary endothelium (16-19), AQP4 (MIWC) in the basolateral membrane of airway epithelium $(20,21)$, and AQP5 in the apical membrane of alveolar type I cells $(22,23)$. Additional water transporters are likely to account for high water permeability of the apical membrane of alveolar and airway epithelia. The mRNA and protein expression of the three known water channels are developmentally regulated in rat lungs $(24,25)$. Transcripts encoding AQPs 1,4 , and 5 are detectable a few days before birth, increase sharply just after birth, and remain elevated through the first week of extrauterine life (25). Maternal treatment with corticosteroids increases fetal AQP1 expression, an effect also seen in the adult lung (24). It is not known if an increase in water channel function and osmotic water movement parallels the changes in mRNA and protein expression.

Although the developmental regulation of AQP expression and the high transalveolar water permeability suggest a role for water channels in lung water balance, they do not provide direct evidence that AQPs are necessary or have a significant physiological role. In particular, humans lacking the Colton

1. Abbreviations used in this paper: ANTS, aminonaphthalene trisulfonic acid; $\mathrm{AQP}$, aquaporin; $\mathrm{E}_{\mathrm{a}}$, activation energy; $\mathrm{ENaC}$, epithelial sodium channels; HBR, Hepes-buffered Ringer's solution; $\mathrm{P}_{\mathrm{d}}$, diffusional water permeability coefficient; $P_{f}$, osmotic water permeability coefficient. 
blood group antigen AQP1 are phenotypically normal (26). Except for AQP2, which, if defective, results in non-X-linked nephrogenic diabetes insipidus (27), a physiological role for the other AQPs has not been established. Membranes that do not contain AQPs have a fairly substantial water permeability through the lipid bilayer; a 5-50-fold increase in water permeability conferred by AQPs might be necessary only for regulated water permeability (e.g., vasopressin-stimulated water permeability in kidney collecting duct), for high water permeability in epithelia separating compartments of different osmolalities, and/or in some cases of near-isosmolar fluid transport. Functional measurements in conjunction with tissue distribution and expression studies are needed to examine the physiological role of water channels.

The purpose of this study was to test the hypothesis that airspace-to-capillary water permeability increases near the time of birth. The rabbit was chosen as a mammalian model in which the fetal lungs are large enough to permit pulmonary artery perfusion and tracheal cannulation. In addition, a substantial body of information is already available on the regulation of extravascular lung water and ion transport in perinatal rabbit lungs and type II cells (9, 28-31). Osmotic water permeability was measured by a surface fluorescence method which was developed recently for quantitative determination of water and solute transport rates in mouse lung (32). The method is based on the change in pleural surface fluorescence from an instilled intraalveolar fluorescent dye in response to osmotically induced movement of water into or out of the alveolar compartment. Osmotic water permeability increased substantially at 12-24 h after birth, remained elevated over the first week of life, and then declined. Functional studies of temperature dependence, mercurial inhibition, and diffusional water permeability supported a role of AQPs in this increase.

\section{Methods}

Animals. Timed-pregnant New Zealand White rabbits were purchased from Grimaud Farms (Stockton, CA). Fetal rabbits were studied at gestational days 27, 29, and 31 (FD27, FD29, and FD31; term = $31 \mathrm{~d})$. For isolation of fetal tissue, pregnant rabbits were anesthetized by $1 \%$ halothane $/ 99 \% \mathrm{O}_{2}$ inhalation. The marginal ear vein was catheterized for administration of pavulon $(0.3 \mathrm{mg} / \mathrm{kg} / \mathrm{h})$. The trachea was cannulated for ventilation, and the carotid artery was catheterized to measure blood pressure and to administer fluids. Fetuses were delivered by cesarean section and used immediately for functional or expression studies. Postnatal rabbits were studied immediately after birth and at 2-6-h intervals during the first $3 \mathrm{~d}$ of extrauterine life, every $24 \mathrm{~h}$ between days 3 and 7, and at days 9, 11, and 21. Tissue for Northern blot analysis was procured at the same postnatal time intervals. One litter contained 9-14 fetuses. 13 litters were studied. Three of these litters were studied prenatally, at FD27, FD29, and FD31. Rabbits from the remaining 10 litters were randomized so that animals from each litter were studied at both early and late postnatal time points.

Lung preparation. Osmotic water movement in isolated lungs was measured using a pleural surface fluorescence method described previously (32). Briefly, perinatal rabbits were anesthetized and exsanguinated. The trachea was cannulated with polyethylene tubing of suitable size for the animal's age. The chest was opened, and the proximal and distal aortas were ligated to ensure no leak through the ductus arteriosus. The pulmonary artery was cannulated with polyethylene tubing of appropriate size and secured. The heart and lungs were removed en bloc to a perfusion chamber mounted on the stage of an epifluorescence microscope. The pulmonary circulation was perfused with Hepes-buffered Ringer's solution (HBR: $137 \mathrm{mM}$ $\mathrm{NaCl}, 2.68 \mathrm{mM} \mathrm{KCl}, 1.25 \mathrm{mM} \mathrm{MgSO}_{4}, 1.82 \mathrm{mM} \mathrm{CaCl}, 5.5 \mathrm{mM}$ glucose, $12 \mathrm{mM}$ Hepes, 1.5\% BSA, pH 7.4, 300 mosM). The perfusion flow rate was adjusted according to gestational or postnatal age, and ranged from 1.5 to $15 \mathrm{ml} / \mathrm{min}$. The outflow pressure from the left atrium was maintained at $0 \mathrm{~cm} \mathrm{H}_{2} \mathrm{O}$. A vasodilator, papavarine (100 $\mu \mathrm{g} / \mathrm{ml})$, was present in the perfusate to ensure adequate perfusion. For measurement of osmotic water permeability, lungs were filled with HBR (300 mosM) containing $1 \mathrm{mg} / \mathrm{ml}$ FITC conjugated to dextran (average mol wt $=70,000$; Sigma Chemical Co., St. Louis, MO). The instilled volumes were (range, based on lung size) FD29, 1.2-1.4 $\mathrm{ml}$; FD31, 1.4-1.9 ml; 0-24 h, 1.6-2.6 ml; 24-48 h, 1.9-2.9 ml; 48-84 h, 2.4-3.6 ml; $1 \mathrm{wk}, 3.8-5.0 \mathrm{ml}$; and $3 \mathrm{wk}, 13-17 \mathrm{ml}$. Before use, unbound FITC was removed using a PD-10-size exclusion column (Pharmacia Biotech AB, Uppsala, Sweden). For measurement of diffusional water permeability, lungs were filled with HBR (300 mosM) containing $2 \mathrm{mM}$ aminonaphthalene trisulfonic acid (ANTS).

Pleural surface fluorescence microscopy. Fluorescence from intraalveolar fluorophores was recorded from a 3-5-mm-diameter spot on the lung pleural surface using an inverted epifluorescence microscope (Diaphot; Nikon, Inc., Melville, NY). The spot was illuminated using a stabilized tungsten-halogen lamp $(75 \mathrm{~W})$ in series with a neutral density filter (OD 1.0), interference filter, and dichroic mirror. A $\times 10$ dry objective (Leitz, numerical aperture 0.25 ) was used for all measurements. Emitted fluorescence was filtered by a cut-on filter and detected by a photomultiplier. Filter wavelength specifications were (interference, dichroic, cut-on) FITC-dextran $(480 \pm 5 \mathrm{~nm}, 510$ $\mathrm{nm},>515 \mathrm{~nm})$, ANTS $(380 \pm 10 \mathrm{~nm}, 430 \mathrm{~nm},>515 \mathrm{~nm})$. The photomultiplier signal was amplified, digitized by a 12-bit analog-to-digital converter interfaced to a PC computer, and filtered at 0.3-s time constant. Data were acquired at $30 \mathrm{~Hz}$, and 30 consecutive samplings were averaged for each point.

Water permeability measurements. The lungs were filled with HBR (300 mosM) containing FITC-dextran, and the pulmonary artery was perfused with HBR. An airspace-to-perfusate osmotic gradient was generated by switching the perfusate to 600 mosM HBR (HBR +300 mosM sucrose), and then back to HBR after several minutes. Previous studies have established the independence of airspace-capillary water permeability on osmotic gradient size and direction (32). The time course of pleural surface fluorescence was monitored continuously. The osmotic water permeability coefficient, $\mathrm{P}_{\mathrm{f}}$, was computed from the equation (32) $P_{\mathrm{f}}=\left[d\left(F / F_{\mathrm{o}}\right) / d t\right]_{\mathrm{t}=0} /\left[\left(S / V_{\mathrm{o}}\right) \mathrm{v}_{\mathrm{w}} \Delta C\right]$, where $[d(F /$ $\left.\left.F_{\mathrm{o}}\right) / d t\right]_{\mathrm{t}=0}$ is the slope of a linear fit to the initial fluorescence time course, $S / V_{\mathrm{o}}$ (surface-to-volume ratio, $\mathrm{cm}^{-1}$ ) is determined from serial confocal micrographs of surface alveoli, $v_{\mathrm{w}}\left(18 \mathrm{~cm}^{3} / \mathrm{mol}\right)$ is the partial molar volume of water, and $\Delta C$ is the difference in osmolality between the airspace and perfusate compartments. For measurement of diffusional water permeability, the airspace was filled with HBR (in $100 \% \mathrm{H}_{2} \mathrm{O}, 300$ mosM) containing $2 \mathrm{mM}$ ANTS, a membrane-impermeant fluorophore whose quantum yield is insensitive to ionic strength and $\mathrm{pH}$, but increases 3.2-fold when $\mathrm{H}_{2} \mathrm{O}$ is replaced with $\mathrm{D}_{2} \mathrm{O}$ (33). The pulmonary artery was initially perfused with isosmolar HBR in $100 \% \mathrm{H}_{2} \mathrm{O}$. The perfusate was then switched to isosmolar HBR prepared in $50 \% \mathrm{H}_{2} \mathrm{O}-50 \% \mathrm{D}_{2} \mathrm{O}$. Diffusional exchange of $\mathrm{D}_{2} \mathrm{O}$ with $\mathrm{H}_{2} \mathrm{O}$ resulted in an increase in intraalveolar $\mathrm{D}_{2} \mathrm{O}$ content and increased ANTS fluorescence. The diffusional water permeability coefficient $\left(\mathrm{P}_{\mathrm{d}}\right)$ was determined from the equation (32) $P_{\mathrm{d}}=$ $\left[d\left(F / F_{\mathrm{o}}\right) / d t\right]_{\mathrm{t}=0}\left[d f_{\mathrm{D}_{2} \mathrm{O}} / d\left(F / F_{\mathrm{o}}\right)\right]_{\mathrm{F}=\mathrm{F}_{\mathrm{o}}} /\left[0.5\left(S / V_{\mathrm{o}}\right)\right]$, where $\left[d f_{\mathrm{D}_{2} \mathrm{O}} / d\left(F / F_{\mathrm{o}}\right)\right]_{\mathrm{F}=\mathrm{F}_{\mathrm{o}}}$ is evaluated from the $f_{\mathrm{D}_{2} \mathrm{O}}$ vs. $F / F_{\mathrm{o}}$ relation above to be 0.69 , and the remaining terms are as defined above.

Confocal microscopy. Pleural surface confocal microscopy was carried out to visualize the FITC-dextran distribution and to determine alveolar geometry, as described previously (32). Alveolar surface-to-volume ratios were computed from serial images acquired 6 $\mu \mathrm{m}$ apart using a three-dimensional image reconstruction procedure (34). The computed ratios were used for computation of $P_{\mathrm{f}}$ and $\mathrm{P}_{\mathrm{d}}$.

RNase protection assay. Lungs were harvested, sliced, frozen immediately in liquid nitrogen, and stored at $-80^{\circ} \mathrm{C}$. Total RNA was 
isolated by the acid guanidinium thiocyanate-phenol-chloroform method. RNase protection assays were performed by a modification of the method described previously $(25,35,36)$. cDNA fragments encoding rabbit AQP1, AQP4, and $\beta$-actin were amplified by PCR, using rabbit lung cDNA as template and primers derived from human and rat AQP sequences. The regions of the PCR-amplified fragments were as follows: AQP1 (nucleotides 1-318), AQP4 (nucleotides 472972), and $\beta$-actin (nucleotides 812-946). Fragments were subcloned into plasmid pGEM-T (Promega Corp., Madison, WI) and confirmed by sequence analysis. ${ }^{2}$ For the RNase protection assay, plasmids were linearized, and antisense RNA probes were synthesized with SP6 RNA polymerase in the presence of $\left[\alpha-{ }^{32} \mathrm{P}\right] \mathrm{CTP}$. For each experiment, $30 \mu \mathrm{g}$ of total rabbit lung RNA was hybridized with $5 \times 10^{4}$ cpm of each ${ }^{32} \mathrm{P}$-labeled cRNA probe at $68^{\circ} \mathrm{C}$ for $10 \mathrm{~min}$, and incubated for $30 \mathrm{~min}$ at $37^{\circ} \mathrm{C}$ in digestion buffer containing RNase $\mathrm{A}(5 \mathrm{U} / \mathrm{ml})$ and RNase $\mathrm{T} 1(200 \mathrm{U} / \mathrm{ml})$. The protected fragments were resolved on a 5\% polyacrylamide gel containing $8 \mathrm{M}$ urea, blotted onto chromatography paper, and exposed to $\mathrm{x}$-ray film with an intensifying screen overnight at room temperature. Rabbit $\beta$-actin was used as an internal control in each lane. Autoradiograms were analyzed by densitometric scanning, using Molecular Analysis software on a Bio-Rad Laboratories image analysis system (Hercules, CA).

Statistics. Statistical comparisons were done with paired or unpaired Student's $t$ test for differences between two groups, and by ANOVA to analyze differences among more than two groups (see figure legends).

\section{Results}

Fig. 1 shows the time course of pleural surface fluorescence in response to changes in perfusate osmolality. Representative original data curves obtained at FD31 and over the first week of extrauterine life are shown. In each curve, there was a prompt rise in fluorescence in response to an increase in perfusate osmolality from 300 to 600 mosM, without a lag phase. The final fluorescence was approximately twice the initial fluorescence, as predicted, with no loss of FITC-dextran from the airspace compartment. The initial rates of fluorescence increase are shown by the dashed lines in each curve. Note the slower initial rates in lungs at FD31 and just after birth ( 1 and $4 \mathrm{~h})$ compared to lungs from older rabbits (12, 36, and $60 \mathrm{~h})$. By $120 \mathrm{~h}$ after birth, the initial rate of fluorescence increase was decreased.

Initial rates of osmotic equilibration were determined for a series of rabbits and time points as summarized in Fig. $2 \mathrm{~A}$. The ordinate is the rate of intraalveolar osmotic equilibration (mosM/s) which depends on $\mathrm{P}_{\mathrm{f}}$ and alveolar geometry (surface-to-volume ratio; see Methods). Note that the rate of osmotic equilibration is the physiologically relevant parameter, whereas $\mathrm{P}_{\mathrm{f}}$ provides information about the intrinsic permeability properties of the airspace-capillary barrier. During the first $12 \mathrm{~h}$ after birth, the rate of osmotic equilibration was significantly less $(1.13 \pm 0.13 \mathrm{mosM} / \mathrm{s})$ than that of the lung at FD29 $(1.95 \pm 0.35 \mathrm{mosM} / \mathrm{s} ; P<0.05)$, but not different from that at FD31 $(1.57 \pm 0.22 \mathrm{mosM} / \mathrm{s} ; P>0.05)$. Equilibration rates increased significantly after $12 \mathrm{~h}$, remained elevated until $84 \mathrm{~h}$ after birth, and then declined to near early postnatal values.

To compute absolute $\mathrm{P}_{\mathrm{f}}$ values, alveolar surface-to-volume ratios were determined by pleural surface confocal microscopy

2. GenBank accession numbers for the rabbit AQP1, AQP4, and $\beta$-actin fragments are AF000311-AF000313.

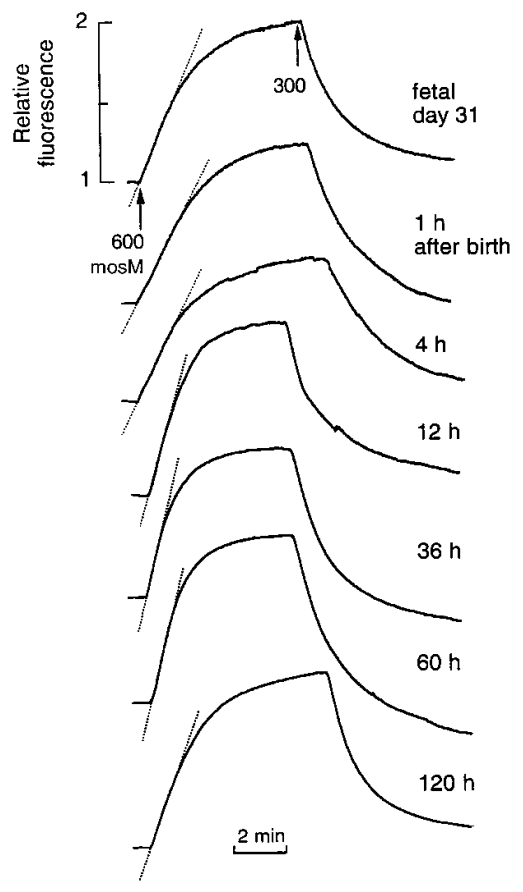

Figure 1. Osmotic water movement between the airspace and capillary compartments in lungs from fetal and newborn rabbits at indicated ages. The airspace was filled with HBR containing $1 \mathrm{mg} / \mathrm{ml}$ FITC-dextran, and the pulmonary artery was perfused at $23^{\circ} \mathrm{C}$. Pleural surface fluorescence was recorded continuously with indicated changes in perfusate osmolality. Dashed lines indicate the initial rate of fluorescence increase in response to changing perfusate osmolality from 300 to 600 mosM. Rates are summarized in Fig. 2 A.

and image reconstruction. Fig. 3, $A-C$, shows surface confocal micrographs of lungs from rabbits at different ages. The airspaces were filled with isosmolar saline containing FITC-dextran, and micrographs from the widest portions of alveoli are shown. The alveolar pattern of fluorescence confirms that the integrated pleural surface fluorescence signal arises primarily from intraalveolar fluorophores. Fig. $3 E$ shows a representative series of confocal micrographs $6 \mu \mathrm{m}$ apart in a 40-h-old lung. Surface-to-volume ratios were computed from such micrographs. The surface-to-volume ratio was $1376 \mathrm{~cm}^{-1}$ at fetal day 29 , and declined over the first week of life, before reaching an estimated adult value of $650 \mathrm{~cm}^{-1}$ (37) (Fig. $3 \mathrm{D}$ ).

Fig. $2 B$ shows $\mathrm{P}_{\mathrm{f}}$ values computed from initial rates of osmotic equilibration (Fig. $2 A$ ) and surface-to-volume ratios (Fig. $3 D$ ). $\mathrm{P}_{\mathrm{f}}$ values were lowest just after birth and increased significantly after $12 \mathrm{~h} . \mathrm{P}_{\mathrm{f}}$ was maximum at $12-84 \mathrm{~h}$ and decreased by $120 \mathrm{~h}$ after birth. These data suggest that the intrinsic water permeability barrier properties of the lung differ between $<12 \mathrm{~h}$ and $>24 \mathrm{~h}$ after birth.

The next set of experiments was done to test the hypothesis that the increased $P_{f}$ involved molecular water channels. Several functional properties of water channels were studied in lungs from $<12$-h- vs. $>48$-h-old rabbits. Fig. $4 A$ shows that osmotic water permeability increased with increasing temperature. The representative original data curves (Fig. $4 \mathrm{~A}$, left) suggest that the temperature sensitivity was greater for the lungs from 10-h-old rabbits. An Arrhenius temperaturedependence plot (Fig. 4 A, right) gave activation energies ( $\left.\mathrm{E}_{\mathrm{a}}\right)$ of $5.6 \pm 0.4$ and $4.2 \pm 0.3 \mathrm{kcal} / \mathrm{mol}(1 \mathrm{cal}=4.184 \mathrm{~J})$ for the $10-\mathrm{h}$ vs. 48-h lungs $(P<0.05)$. In general, a lower $\mathrm{E}_{\mathrm{a}}$ suggests the involvement of molecular water channels $(15,38)$. However, absolute $E_{a}$ values cannot be interpreted unambiguously for the complex airspace-capillary barrier because of the presence of several membrane and diffusive barriers in series.

The ability of mercurial compounds to inhibit osmotic water permeability has been taken as evidence for the involve- 

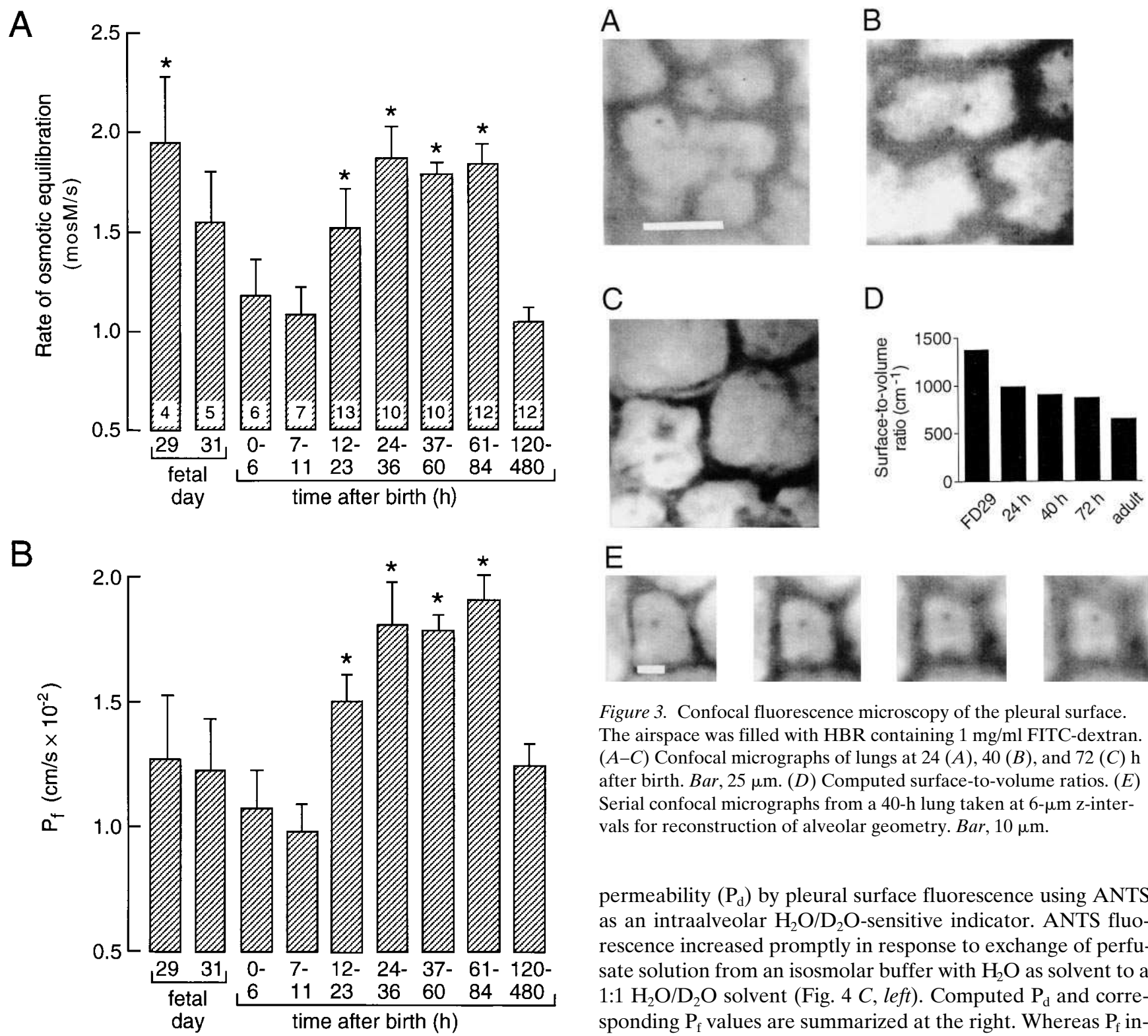

E
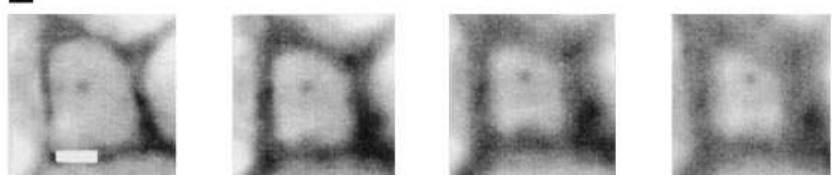

Figure 3. Confocal fluorescence microscopy of the pleural surface. The airspace was filled with HBR containing $1 \mathrm{mg} / \mathrm{ml}$ FITC-dextran. $(A-C)$ Confocal micrographs of lungs at $24(A), 40(B)$, and $72(C) \mathrm{h}$ after birth. Bar, $25 \mu \mathrm{m}$. (D) Computed surface-to-volume ratios. $(E)$ Serial confocal micrographs from a 40 -h lung taken at 6- $\mu \mathrm{m}$ z-intervals for reconstruction of alveolar geometry. Bar, $10 \mu \mathrm{m}$.

permeability $\left(\mathrm{P}_{\mathrm{d}}\right)$ by pleural surface fluorescence using ANTS as an intraalveolar $\mathrm{H}_{2} \mathrm{O} / \mathrm{D}_{2} \mathrm{O}$-sensitive indicator. ANTS fluorescence increased promptly in response to exchange of perfusate solution from an isosmolar buffer with $\mathrm{H}_{2} \mathrm{O}$ as solvent to a 1:1 $\mathrm{H}_{2} \mathrm{O} / \mathrm{D}_{2} \mathrm{O}$ solvent (Fig. 4 C, left). Computed $\mathrm{P}_{\mathrm{d}}$ and corresponding $P_{f}$ values are summarized at the right. Whereas $P_{f}$ increased remarkably in lungs from 6- to 60-h-old rabbits, $P_{d}$ did not change. Taken together with the temperature-dependence and mercurial inhibition results, these data provide functional evidence for the involvement of molecular water channels in the perinatal increase in lung water permeability (see Discussion).

Fig. $4 D$ shows the effect of perfusion flow rate and instillate volume on $\mathrm{P}_{\mathrm{f}}$. Lungs were perfused at the flow rates used in the above experiments and at twice those values. Doubling of flow rate did not alter the measured $P_{\mathrm{f}}$ of lungs at the four ages examined. In addition, $\mathrm{P}_{\mathrm{f}}$ did not depend on the volume of test solution instilled into the airspaces. These control experiments indicate that $P_{f}$ is not sensitive to perfusion rates and filling volumes under the conditions of our experiments.

Experiments were done to confirm the increased expression of molecular water channels in perinatal rabbit lung, as was done previously for rat lung (25). It is recognized, however, that all lung water transporters have not been identified (see Introduction), so quantitative comparisons of protein expression with water permeability are not possible. Because mammalian AQP water channels have been cloned thus far 

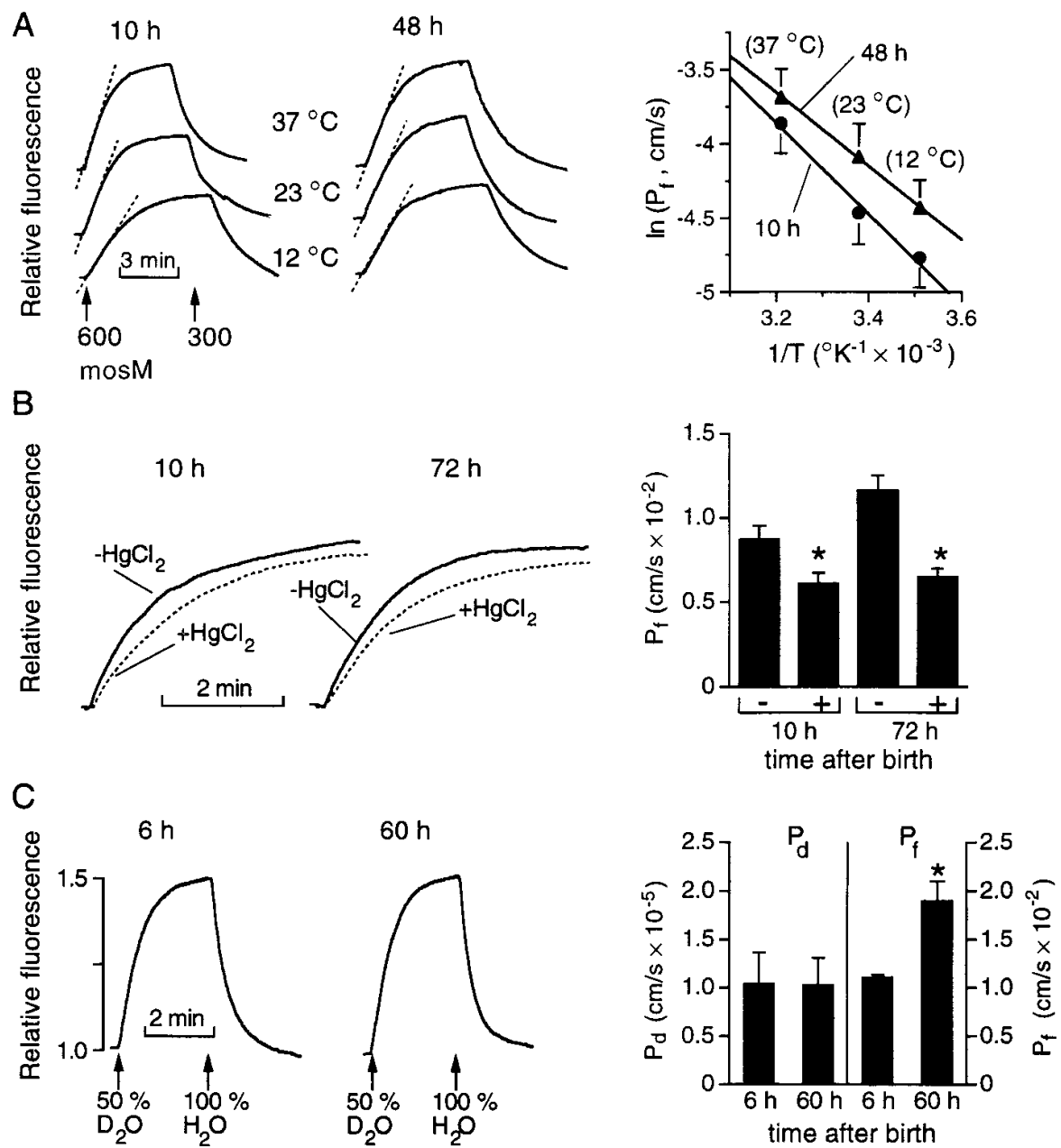

Figure 4. Properties of osmotic $\left(\mathrm{P}_{\mathrm{f}}\right)$ and diffusional $\left(\mathrm{P}_{\mathrm{d}}\right)$ water permeability in perinatal lungs. $(A)$ Temperature dependence. (Left) Representative surface fluorescence data in 10 - vs. 48 -h postnatal lungs at the indicated perfusion temperatures. (Right) Arrhenius plot of temperature-dependence data $\left(\mathrm{P}_{\mathrm{f}}\right.$, mean $\left.\pm \mathrm{SE}, n=3\right)$ with slopes $\left(\mathrm{E}_{\mathrm{a}}\right)$ of $5.6 \pm 0.4$ and $4.2 \pm 0.3 \mathrm{kcal} /$ mol, respectively $(1 \mathrm{cal}=4.184 \mathrm{~J}) .(B)$ Mercurial inhibition. (Left) Osmotic water movement at $14^{\circ} \mathrm{C}$ in the absence and presence of $0.5 \mathrm{mM} \mathrm{HgCl}_{2}$ (added to perfusate). (Right) Summary of $\mathrm{P}_{\mathrm{f}}$ values. *Significant inhibition, $P<0.05$, paired $t$ test. (C) Diffusional water permeability. (Left) The airspace was filled with HBR containing $2 \mathrm{mM}$ ANTS, and the pulmonary artery was perfused at $23^{\circ} \mathrm{C}$. The time course of ANTS fluorescence in response to addition and removal of $50 \% \mathrm{D}_{2} \mathrm{O}$ to the isosmolar perfusate is shown. (Right) Summary of $\mathrm{P}_{\mathrm{d}}$ and $\mathrm{P}_{\mathrm{f}}$ data. *Significant difference from 6-h data, $P<0.05$, unpaired $t$ test. $(D)$ Dependence of $\mathrm{P}_{\mathrm{f}}$ on perfusion flow rate and instillate volume. (Left) Lungs at indicated ages were perfused at the indicated standard flow rate or twice that value. (Right) At $12 \mathrm{~h}$ after birth, $\mathrm{P}_{\mathrm{f}}$ was measured in lungs instilled with indicated volumes.

only from mouse, rat, and human sources, it was necessary to identify rabbit AQPs. The PCR/homology cloning strategy with degenerate as well as specific primers was used with rabbit lung cDNA as template. After extensive experimentation to identify AQP-like proteins in rabbit lung, two cDNA fragments were obtained with 89 and $88 \%$ DNA identity to rat AQP1 and AQP4, respectively. No cDNAs corresponding to AQP5 were identified. As a control transcript, a fragment of rabbit $\beta$-actin was cloned by homology to rat $\beta$-actin. Fig. $5 A$ shows an RNase protection assay autoradiogram of AQP1 and AQP4 transcripts in perinatal rabbit lung. From two independent sets of experiments on separate lung preparations, quantitative densitometry in Fig. $5 B$ shows a strong increase in AQP1 transcript soon after birth, similar to results reported in rat lung $(24,25)$. A less pronounced increase in AQP4 transcript expression was found here in rabbit than in rat (25).

\section{Discussion}

Several lines of evidence have suggested a physiological role for AQPs in lung fluid balance, including the specific expression pattern of AQPs in fluid-transporting epithelia and endothelia (16-23), and the high transalveolar $(18,32)$ and distal airway (21) water permeabilities in the adult lung. In the developing lung, AQP expression increases sharply near the time of birth (25), and expression of one of the AQPs (AQP1) is upregulated by corticosteroids (24). It has been proposed that AQPs may be involved in the transition from a fluid-secreting to a fluid-reabsorbing lung near the time of birth (24). This hypothesis yields several testable predictions that involve functional measurements of water permeability between the airspace and capillary compartments: $(a)$ water permeability should increase near the time of birth, $(b)$ the increased water 


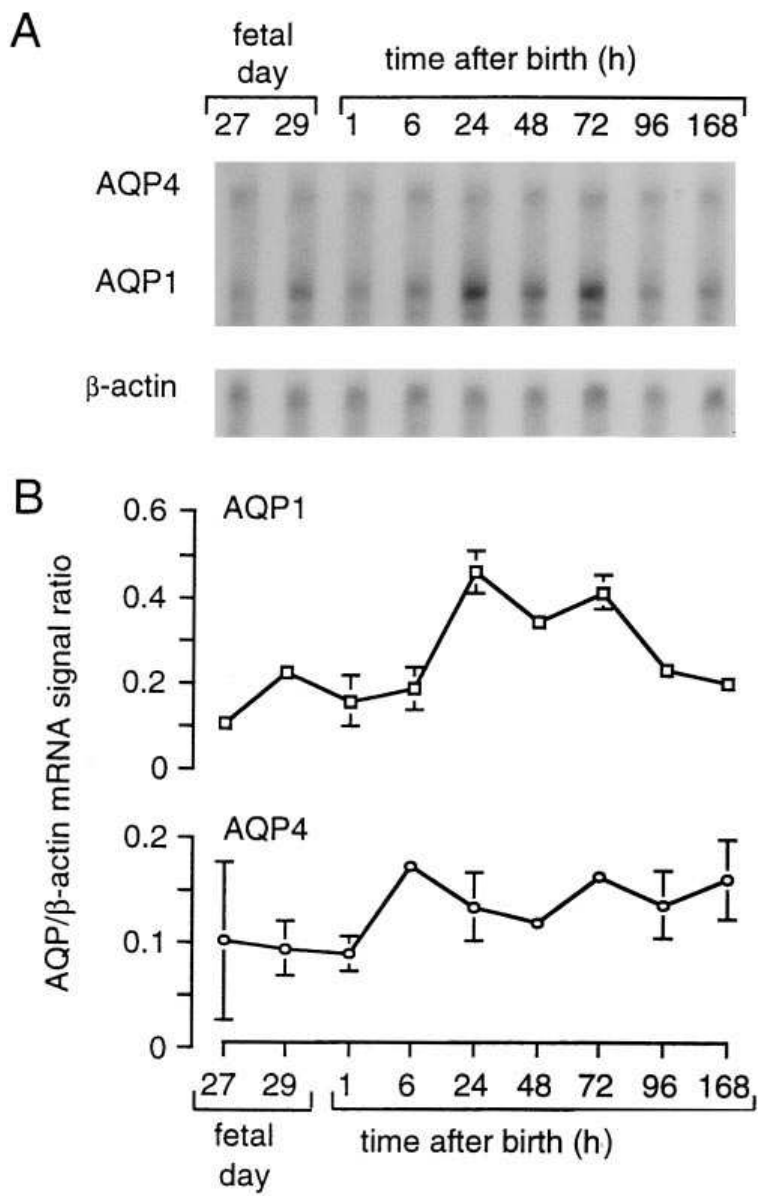

Figure 5. RNase protection assay of water channel expression in lung. ( $A$ ) RNase protection assays were done on fetal (days FD27 and FD29) and postnatal lung tissue $(1,6,24,48,72,96 \mathrm{~h}$, and $7 \mathrm{~d})$ as described in Methods. Each sample was hybridized to AQP1, AQP4, and $\beta$-actin probes. (B) Summary of quantitative results. The ordinate is the ratio of water channel transcript expression relative to that of $\beta$-actin as measured by densitometry.

permeability should correlate with the expression of AQP(s) comprising the rate-limiting water permeability barrier, and (c) deletion of certain AQPs should be associated with abnormal perinatal alveolar fluid clearance. It is already known that absence of AQP1 in humans is not associated with overt clinical abnormalities (26); this finding is consistent with the ratelimiting barrier for capillary-to-airspace water movement being the alveolar epithelium, rather than the endothelium where AQP1 is primarily expressed (16-19). Recently, a transgenic knockout mouse deficient in AQP4 has been generated (41), and lung phenotype analysis is in progress.

The purpose of this study was to test prediction $a$ and to begin to examine prediction $b$ by functional measurements of lung water permeability and analysis of lung water channel expression. The principal finding was that osmotic water permeability increased significantly at $12-24 \mathrm{~h}$ after birth and remained elevated for the next $4 \mathrm{~d}$. In addition, functional and expression evidence provided support for a role of molecular water channels in this increased osmotic water permeability. Compared to newborn lungs, lungs from 48-h-old rabbits had higher osmotic water permeability, which was inhibited to a greater extent by $\mathrm{HgCl}_{2}$ and was less temperature dependent. The increased osmotic water permeability was not associated with increased diffusional water permeability. Because lung diffusional water permeability is unstirred layer limited (32), the constancy of $\mathrm{P}_{\mathrm{d}}$ indicates adequacy of the perfusion and correct normalization for alveolar geometry. These studies provide the first functional evidence for developmentally regulated water permeability in perinatal lung and suggest the involvement of molecular water channels in this regulation.

The measurement of osmotic water permeability between the airspace and capillary compartments involved determination of airspace osmolality as a function of time in response to an imposed osmotic gradient between airspace and capillary fluid. In our initial study in the in situ perfused sheep lung (18), airspace fluid samples were obtained by intratracheal catheterization after instillation of hyperosmolar (900 mosM) fluid into the airspaces. Airspace osmolality equilibrated rapidly $\left(\mathrm{t}_{1 / 2}\right.$ $\sim 45 \mathrm{~s}$ ), was weakly temperature dependent, and was inhibited reversibly by $\mathrm{HgCl}_{2}$. It was concluded that transalveolar water transport was transcellular and involved mercurial-sensitive water channels. This approach was adapted to small animals by determination of airspace osmolality from the pleural surface fluorescence signal generated by an airspace fluorescent probe (32). The measurement of pleural surface fluorescence provided excellent time resolution $(<1 \mathrm{~s})$ because airspace fluid sampling is not required and osmotic gradients can be generated rapidly by changing pulmonary artery perfusates. Water permeability properties of mouse lung measured by the surface fluorescence method (32) were similar to those in sheep lung (18). The surface fluorescence method was adapted to the perinatal rabbit lung as early as fetal day 29. However, it was found that perfusion of the prenatal lung was challenging because of tissue fragility, and perfusion of lungs from fetal day 27 and earlier was not possible because of high pulmonary vascular resistance.

The movement of water across the perinatal blood-gas barrier is important for several reasons. First, the lungs secrete substantial amounts of fluid in utero. Just before birth, the potential air spaces contain $20-30 \mathrm{ml} / \mathrm{kg}$ body wt of fluid (42-45). In sheep, the flow rate of secreted tracheal liquid is $\sim 5 \mathrm{ml} / \mathrm{h} /$ $\mathrm{kg}$ body wt at term $(45,46)$. The fluid secretion is driven by active chloride transport across the lumenal membrane $(45,47$, 48). Fluid secretion and maintenance of its specific composition may be important for lung morphogenesis (49-51). Second, at the onset of labor shortly before birth, fluid absorption occurs, which is driven by active sodium transport $(3,52)$. Fluid absorption is important to prepare the lungs for alveolar respiration at birth. Although $\sim 50 \%$ of extravascular lung water is reabsorbed at birth, and $>80 \%$ by $12 \mathrm{~h}$ after birth, it is still slightly elevated at $24 \mathrm{~h}$ after birth $(8,9)$. Finally, proper hydration of the airways and alveolar lumenal surface in the postnatal lung requires a balance between fluid secretion and absorption. Although the mechanisms regulating airspace hydration in the adult lung remain poorly understood, it is likely that specific ion and water transporters along the pulmonary epithelium from the trachea to the alveoli are involved.

The fluid secretion and reabsorption processes in the perinatal distal airway and alveolar epithelium are the result of the coordinated action of distinct transport proteins. Fluid secretion is driven by active chloride transport, where chloride enters the epithelial cells across the basolateral $\mathrm{Na}-\mathrm{K}-2 \mathrm{Cl}$ cotransporter and is extruded across the apical membrane by 
two or more classes of chloride channels (e.g., CFTR and ClC-2) (3, 53-55). Movement of chloride osmotically drives water from the vascular and interstitial compartments to the airspace compartment. When absorption becomes the dominating transport event during labor, sodium enters the epithelial cells via apical sodium channels $(\mathrm{ENaC})(4)$ and is extruded across the basolateral membrane via the $\mathrm{Na}, \mathrm{K}$-ATPase, resulting in osmotically driven water absorption from the airspaces. The presence of water channels in the alveolar epithelium and capillary endothelium could facilitate osmotic water movement during these perinatal events.

These processes appear to be regulated in development by the differential expression of the primary ion transport proteins, and probably the water transporting AQPs. In fetal rabbit and human, CFTR transcript and protein is present from an early stage of lung development, suggesting that it may be functionally important for fluid production in the fetal lung $(54,55)$. In rat, transcript levels of the $\mathrm{ClC}-2 \mathrm{Cl}^{-}$channel are high in late gestation, decrease markedly after birth, and become undetectable in the adult (53). However, a functional role for $\mathrm{ClC}-2$ has not yet been established. Over the same time period, there is induction of the three subunits of the rat epithelial $\mathrm{Na}^{+}$channel ( $\alpha-, \beta-$, and $\gamma$-rENaC; reference 56$)$, as well as both subunits ( $\alpha$ and $\beta$ ) of the Na,K-ATPase (57-59). These changes in ion transporter expression are in general agreement with the few reported functional measurements of ion transport in prenatal and postnatal lung $(60,61)$. The expression and function of AQPs in the perinatal lung appears to parallel that of the two principal sodium transporters, ENaC and the Na,K-ATPase; however, the expression data alone do not prove a role for AQPs in perinatal lung water permeability.

The relatively low $\mathrm{P}_{\mathrm{f}}$ at birth compared to the higher levels observed at fetal day 31 and 12-24 h after birth is not necessarily what would be predicted from data on perinatal lung liquid clearance (9). The majority of fetal lung water is cleared by the time of birth $(3,9)$, although fluid clearance continues during the early hours after birth. Therefore, adequate water conductive pathways (either AQP or non-AQP) should exist to facilitate early postnatal (0-12-h) water movement. It should be noted that even at its lowest, the apparent $P_{\mathrm{f}}$ in the first $12 \mathrm{~h}$ after birth was still quite high. Therefore, osmotic water permeability is probably not rate-limiting for the clearance of fetal lung liquid. The increased water permeability and AQP expression between 12 and $84 \mathrm{~h}$ may facilitate the maintenance of dry airspaces by near-isosmolar fluid reabsorption mechanisms. However, despite considerable work on near-isosmolar fluid transport over several decades, our understanding remains inadequate to predict how $\mathrm{P}_{\mathrm{f}}$ would affect transepithelial fluid transport rates. Therefore, although the results in this study provide the first functional data on perinatal lung water permeability and suggest the involvement of molecular water channels, it is not yet possible to integrate the experimental results into a unified mechanism for regulation of airspace hydration.

\section{Acknowledgments}

We thank Dr. Chrystelle Garat for assistance in developing the perinatal perfusion preparation, Dr. Javier Farinas for the confocal microscopy, and Mr. Oscar Osorio for surgical assistance in the preterm experiments.
This work was supported by grants HL-51854, HL-42368, and DK-35124 from the National Institutes of Health, and grant R613 from the National Cystic Fibrosis Foundation. Dr. E.P. Carter was supported by a fellowship from the American and California Lung Associations, and Dr. F. Umenishi by a fellowship from the National Kidney Foundation.

\section{References}

1. Adamson, T.M., R.D.H. Boyd, H.S. Platt, and L.B. Strang. 1969. Composition of alveolar liquid in the foetal lamb. J. Physiol. (Lond.). 204:159-168.

2. Dickson, K.A., J.E. Maloney, and P.J. Berger. 1986. Decline in lung liquid volume before labor in fetal lambs. J. Appl. Physiol. 61:2266-2272.

3. Bland, R.D. 1990. Lung epithelial ion transport and fluid movement during the perinatal period. Am. J. Physiol. 259:L30-L37.

4. Hummler, E., P. Barker, J. Gatzy, F. Beermann, C. Verdumo, A. Schmidt, R. Boucher, and B.C. Rossier. 1996. Early death due to defective neonatal lung liquid clearance in alpha-ENaC-deficient mice. Nat. Genet. 12:325328 .

5. Walters, D.V., and R.E. Olver. 1978. The role of catecholamines in lung liquid absorption at birth. Pediatr. Res. 12:239-242.

6. Barker, P.M., and J.T. Gatzy. 1993. Effect of gas composition on liquid secretion by explants of distal lung of fetal rat in submersion culture. Am. J. Physiol. 265:L512-L517.

7. Pitkänen, O., A.K. Transwell, G. Downey, and H. O'Brodovich. 1996. Increased $\mathrm{PO}_{2}$ alters the bioelectric properties of fetal distal lung epithelium. Am. J. Physiol. 270:L1060-L1066.

8. Adams, F.H., M. Yanagisawa, D. Kuzela, and H. Martinek. 1971. The disappearance of fetal lung fluid following birth. J. Pediatr. 78:837-843.

9. Bland, R.D., D.D. McMillan, M.A. Bressack, and L. Dong. 1980. Clearance of liquid from lungs of newborn rabbits. J. Appl. Physiol. 49:171-177.

10. O'Brodovich, H., V. Hannam, M. Seear, and J.B.M. Mullen. 1990. Amiloride impairs lung water clearance in newborn guinea pigs. J. Appl. Physiol. 68:1758-1762.

11. Matthay, M.A., C.C. Landolt, and N.C. Staub. 1982. Differential liquid and protein clearance from the alveoli of anesthetized sheep. J. Appl. Physiol. 53:96-104.

12. Basset, G., C. Crone, and G. Saumon. 1987. Fluid absorption by rat lung in situ: pathways for sodium entry in the luminal membrane of alveolar epithelium. J. Physiol. (Lond.) 384:325-345.

13. Matthay, M.A., H.G. Folkesson, and A.S. Verkman. 1996. Salt and water transport across alveolar and distal epithelia in the adult lung. Am. J. Physiol. 270:L487-L503.

14. Knepper, M.A. 1994. The aquaporin family of molecular water channels. Proc. Natl. Acad. Sci. USA. 91:6255-6258.

15. Verkman, A.S., A.N. Van Hoek, T. Ma, A. Frigeri, W.R. Skach, A. Mitra, T.K. Tamarappoo, and J. Farinas. 1996. Water transport across mammalian cell membranes. Am. J. Physiol. 270:C12-C30.

16. Nielsen, S., B.L. Smith, E.I. Christensen, and P. Agre. 1993. Distribution of the aquaporin CHIP in secretory and resorptive epithelia and capillary endothelia. Proc. Natl. Acad. Sci. USA. 90:7275-7279.

17. Hasegawa, H., S.C. Lian, W.E. Finkbeiner, and A.S. Verkman. 1994 Extrarenal tissue distribution of CHIP28 water channels by in situ hybridization and antibody staining. Am. J. Physiol. 266:C893-C903.

18. Folkesson, H.G., M.A. Matthay, H. Hasegawa, F. Kheradmand, and A.S. Verkman. 1994. Transcellular water transport in lung alveolar epithelium through mercury-sensitive water channels. Proc. Natl. Acad. Sci. USA. 91:49704974.

19. Schnitzer, J.E., and P. Oh. 1996. Aquaporin-1 in plasma membrane and caveolae provides mercury-sensitive water channels across lung endothelium. Am. J. Physiol. 270:H416-H422.

20. Frigeri, A., M.A. Gropper, C.W. Turck, and A.S. Verkman. 1995. Immunolocalization of the mercurial-insensitive water channel and glycerol intrinsic protein in epithelial cell plasma membranes. Proc. Natl. Acad. Sci. USA. 92: $4328-4331$.

21. Folkesson, H.G., M.A. Matthay, A. Frigeri, and A.S. Verkman. 1996. High transcellular water permeability in microperfused distal airways. Evidence for channel-mediated water transport. J. Clin. Invest. 97:664-671.

22. King, L.S., S. Nielsen, and P. Agre. 1996. Aquaporin-5 is expressed in rat type I pneumocytes. Am. J. Respir. Crit. Care Med. 153:A508. (Abstr.)

23. Zhang, X.-L., Z. Borok, R.L. Lubman, S.I. Danto, S. Zabski, L.S. King, P.C. Agre, and E.D. Crandall. 1996. Expression of aquaporin-5 in alveolar epithelial cells. Am. J. Respir. Crit. Care Med. 153:A508 (Abstr.)

24. King, L.S., S. Nielsen, and P. Agre. 1996. Aquaporin-1 water channel protein in lung-ontogeny, steroid-induced expression, and distribution in rat. $J$. Clin. Invest. 97:2183-2191.

25. Umenishi, F., E.P. Carter, B. Yang, B. Oliver, M.A. Matthay, and A.S Verkman. 1996. Sharp increase in rat lung water channel expression in the perinatal period. Am. J. Respir. Cell Mol. Biol. 15:673-679.

26. Preston, G.M., B.L. Smith, M.L. Zeidel, J.J. Moulds, and P. Agre. 1994. 
Mutations in aquaporin-1 in phenotypically normal human without functional CHIP water channels. Science (Wash. DC). 265:1585-1587.

27. Deen, P.M.T., M.A.J. Verkijk, N.V.A.M. Knoers, B. Wieringa, L.A.H. Monnens, C.H. van Os, and B.A. van Oost. 1994. Requirement of human renal aquaporin-2 for vasopressin-dependent concentration of urine. Science (Wash. DC). 155:92-95.

28. Bland, R.B., M.A. Bressack, and D.D. McMillan. 1979. Labor decreases the lung water content of newborn rabbits. Am. J. Obstet. Gynecol. 135:364367.

29. Bland, R.D., and C.A.R. Boyd. 1986. Cation transport in lung epithelial cells derived from fetal, newborn and adult rabbits. J. Appl. Physiol. 61:507515 .

30. Zeitlin, P.L., G.M. Loughlin, and W.B. Guggino. 1988. Ion transport in cultured fetal and adult rabbit tracheal epithelium. Am. J. Physiol. 254:C691C698.

31. Chapman, D.L., J.H. Widdicombe, and R.D. Bland. 1990. Developmental differences in rabbit lung epithelial cell $\mathrm{Na}^{+}-\mathrm{K}^{+}$-ATPase. Am. J. Physiol. 259:L481-L487.

32. Carter, E.P., M.A. Matthay, J. Farinas, and A.S. Verkman. 1996. Transalveolar osmotic and diffusional water permeability in intact mouse lung measured by a novel surface fluorescence method. J. Gen. Physiol. 108:133-142.

33. Kuwahara, M., and A.S. Verkman. 1988. Direct fluorescence measurement of diffusional water permeability in the vasopressin-sensitive kidney collecting tubule. Biophys. J. 54:587-593.

34. Farinas, J., V. Simanek, and A.S. Verkman. 1995. Cell volume measured by total internal reflection microfluorimetry: application to water and solute transport in cells transfected with water channel homologs. Biophys. J. 68:16131620.

35. Frigeri, A., M.A. Gropper, F. Umenishi, M. Katsura, D. Brown, and A.S. Verkman. 1995. Localization of MIWC and GLIP water channel homologs in neuromuscular, epithelial, and glandular tissues. J. Cell Sci. 108:2993-3002.

36. Umenishi, F., A.S. Verkman, and M. Gropper. 1996. Quantitative analysis of aquaporin mRNA expression in rat tissues. DNA Cell Biol. 15:475-480.

37. Milsom, W.K. 1989. Comparative Pulmonary Physiology: Current Concepts, Volume 39. Marcel Dekker, Inc., New York.

38. Finkelstein, A. 1987. Water Movement Through Lipid Bilayers, Pores, and Plasma Membranes: Theory and Reality. John Wiley \& Sons Inc., New York.

39. Van Hoek, A.N., and A.S. Verkman. 1992. Functional reconstitution of the isolated erythrocyte water channel CHIP28. J. Biol. Chem. 267:1826718269.

40. Raina, S., G.M. Preston, W.B. Guggino, and P. Agre. 1995. Molecular cloning and characterization of an aquaporin cDNA from salivary, lacrimal, and respiratory tissues. J. Biol. Chem. 270:1908-1912.

41. Ma, T., B. Yang, A. Gillespie, E.J. Carlson, C.J. Epstein, and A.S. Verkman. 1997. Generation and phenotype of a transgenic knockout mouse lacking the mercurial-insensitive water channel aquaporin-4. J. Clin. Invest. 100:957962.

42. Humphreys, P.W., I.C.S. Normand, E.O.R. Reynolds, and L.B. Strang. 1967. Pulmonary lymph flow and the uptake of liquid from the lungs of the lamb at the start of breathing. J. Physiol. (Lond.). 193:1-29.

43. Normand, I.C.S., R.E. Olver, E.O.R. Reynolds, and L.B. Strang. 1971 Permeability of lung capillaries and alveoli to nonelectrolytes in the fetal lamb. J. Physiol. (Lond.). 219:303-330.
44. Normand, I.C.S., E.O.R. Reynolds, and L.B. Strang. 1970. Passage of macromolecules between alveolar and interstitial spaces in foetal and newly ventilated lungs of the lamb. J. Physiol. (Lond.). 210:151-164.

45. Olver, R.E., E.E. Schneeberger, and D.V. Walters. 1981. Epithelial solute permeability, ion transport and tight junction morphology in the developing lung of the fetal lamb. J. Physiol. (Lond.). 315:395-412.

46. Kitterman, J.A., P.L. Ballard, J.A. Clements, E.J. Mescher, and W.H. Tooley. 1979. Tracheal fluid in fetal lambs: spontaneous decrease prior to birth J. Appl. Physiol. 47:985-989.

47. Olver, R.E., and L.B. Strang. 1974. Ion fluxes across the pulmonary epithelium and the secretion of lung liquid in the foetal lamb. J. Physiol. (Lond.). 241:327-357.

48. Cassin, S., G. Gause, and A.M. Perks. 1986. The effects of bumetanide and furosemide on lung liquid secretion in fetal sheep. Proc. Soc. Exp. Biol. Med. 181:427-431.

49. Alcorn, D., T.M. Adamson, T.F. Lambert, J.E. Maloney, B.C. Ritchie, and P.M. Robinson. 1977. Morphological effects of chronic tracheal ligation and drainage in the fetal lamb lung. J. Anat. 123:649-660.

50. Wallen, L.D., S.F. Perry, J.T. Alson, and J.E. Maloney. 1990. Morphometric study of the role of pulmonary arterial flow in fetal lung growth in sheep. Pediatr. Res. 27:122-127.

51. Dickson, K.A., and R. Harding. 1989. Decline in lung liquid volume and secretion rate during oligohyramnios in fetal sheep. J. Appl. Physiol. 67:24012407.

52. O'Brodovich, H. 1991. Epithelial ion transport in the fetal and perinatal lung. Am. J. Physiol. 261:C555-C564.

53. Murray, C.B., M.M. Morales, T.R. Flotte, S.A. McGrath-Morrow, W.B Guggino, and P.L. Zeitlin. 1995. ClC-2: a developmentally dependent chloride channel expressed in the fetal lung and downregulated at birth. Am. J. Respir. Cell Mol. Biol. 12:597-604.

54. McCray, P.B., Jr., W.W. Reenstra, E. Louie, J. Johnson, J.D. Bettencourt, and J. Bastacky. 1992. Expression of CFTR and presence of cAMP-mediated fluid secretion in human fetal lung. Am. J. Physiol. 262:L472-L481.

55. McGrath, S.A., A. Basu, and P.L. Zeitlin. 1993. Cystic fibrosis gene and protein expression during fetal lung development. Am. J. Respir. Cell Mol. Biol. 8:201-208.

56. Tchepichev, S., J. Ueda, C. Canessa, B.C. Rossier, and H. O'Brodovich. 1995. Lung epithelial $\mathrm{Na}$ channel subunits are differentially regulated during development and by steroids. Am. J. Physiol. 269:C805-C812.

57. Orlowski, J., and J.B. Lingrel. 1988. Tissue-specific and developmental regulation of rat $\mathrm{Na}, \mathrm{K}-\mathrm{ATPase}$ catalytic alpha isoform and beta subunit mRNAs. J. Biol. Chem. 263:10436-10442.

58. Ingbar, D.H., C.B. Weeks, M. Gilmore-Herbert, E. Jacobsen, S. Duvick, R. Dowin, S.K. Savick, and J.D. Jamieson. 1996. Developmental regulation of Na,K-ATPase in rat lung. Am. J. Physiol. 270:L619-L629.

59. O'Brodovich, H., O. Staub, B.C. Rossier, K. Geering and J.P. Kraehenbuhl. 1993. Ontogeny of $\alpha_{1}$ and $\beta_{1}$-isoforms of $\mathrm{Na}^{+}-\mathrm{K}^{+}$-ATPase on fetal distal rat lung epithelium. Am. J. Physiol. 264:C1137-C1143.

60. Krochmal, E.M., S.T. Ballard, J.R. Yankaskas, R.C. Boucher, and J.T. Gatzy. 1989. Volume and ion transport by fetal rat alveolar and tracheal epithelia in submersion culture. Am. J. Physiol. 256:F397-F407.

61. Rao, A.K., and G.R. Cott. 1991. Ontogeny of ion transport across fetal pulmonary epithelial cells in monolayer culture. Am. J. Physiol. 261:L178L187. 